\title{
Description of a New Species of Melittomma (Coleoptera: Lymexylidae) from Honduras
}

\author{
Jesús Orozco ${ }^{1}$ and Dafna Díaz ${ }^{2}$
}

\begin{abstract}
A new species of lymexylid in the genus Melittomma Murray is described from Honduras. With the addition of this species, three species in the family are now known in the country. A key to the three Honduran species is included.
\end{abstract}

Keywords: Central America, diversity, forest, ship-timber beetle.

\section{Descripción de una Nueva Especie de Melittomma (Coleoptera: Lymexylidae) de Honduras}

Resumen. Se describe una nueva especie de lymexylido del género Melittomma Murray de Honduras. Con esta son tres las especies de esta familia que se conocen en el país. Se presenta una clave para la identificación para las tres especies.

Palabras clave: América Central, bosque, diversidad, escarabajos.

\section{Introduction}

Lymexylidae is small family of beetles with around 60 species some of which are important pests of trees. Atractocerus brasiliensis (Lepeletier \& AudinetServille), for example, a species recorded in mango and other trees, was recently found in the pine Pinus oocarpa Schiede (Casari and Teixeira, 2011) in Brazil. Female lymexylids lay their eggs on wood where the larvae develops and pupation takes place. The larvae feed on fungus they grow in their tunnels, spending sometimes more than 2 years inside the tree. Adults are known to be short lived (Wheeler 1986).

Thirteen species included in four genera (Atractocerus, Fusicornis, Melittomma and Melittommopsis) are recorded from the Neotropical region (Casari \& Teixeira 2011). In Honduras two species are known: Atractocerus brasiliensis and Melittomma brasiliense (Laporte). A third species from Pico Bonito National Park, Atlántida, Honduras is described here.

\section{Materials and Methods}

Internal and external morphological characters were studied. Specimens were examined using a Leica EZ4 dissecting microscope. Genitalia were extracted by previously relaxing the specimen in hot water. Genitalia were placed in a glycerin-filled vial during the study and posteriorly card-mounted under the specimen.

The type material is deposited at Zamorano's Insect Collection (EAPZ) in Zamorano, Honduras.

\section{Melittomma pilzi Orozco \& Díaz, New Species (Figures 1-3)}

\begin{abstract}
Type material (2). Male holotype labeled "HONDURAS: Atlántida/ Parq Nc Pico Bonito/ Cerro Miramar 550m/ N15 $34^{\prime} 01^{\prime \prime} \mathrm{N}$ W87 $03^{\prime} 57^{\prime} /$ 14-15 Agosto 2001/ Cave, Cordero \& Machado/ 65.301 EAPZ" and with our red holotype label. Female allotype labeled "HONDURAS: Atlántida/ Parq Nc Pico Bonito/ Cerro

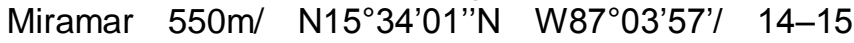
Agosto 2001/ Cave, Cordero \& Machado/ 65.302 EAPZ" and with our yellow paratype label.
\end{abstract}

Description. Holotype male (Figures 1-2). Length $10 \mathrm{~mm}$ (measuring from vertex to tip of abdomen). Color light brown. Body abundantly covered by short, tawny setae, distal abdominal segments sparsely setose (Figure 1A). Head: Oval in shape, being wider than longer, with a neck at base. Eyes large, covering most of the head, broadly touching in front, separated at vertex (Figure 1B). Antennae 11-segmented, setose, antennomeres 3-11 serrate (Figure 1C). Frons reduced, inconspicuous. Labrum short, U-shaped.

\footnotetext{
1 Insect Collection. Panamerican School of Agriculture (Zamorano University), Science and Production Department. Zamorano, Francisco Morazán, Honduras. E-mail: jorozco@zamorano.edu

2 Insect Collection. Panamerican School of Agriculture (Zamorano University), Science and Production Department. Zamorano, Francisco Morazán, Honduras. E-mail: dafna05espinoza@gmail.com
} 
Mandibles broad. Labrum and mandibles both covered by yellow, long setae. Maxillary palps long, almost as long as antennae; palpomeres II and III, large; palporgan branched (Figure 1D). Labial palps short, 3segmented. Thorax: Pronotum longer than wide, abundantly setose, sides dark (Figure 6). Anterior margin curved posteriorly; posterior margin weakly sinuate, curved; sides subparallel. Scutellum quadrate. Pro- and mesocoxae large, subequal to respective femur. Metacoxae small. Trochanters visible. Tibial spur formula 0-2-2. Elytra soft, covering half of penultimate abdominal tergite, last abdominal tergite completely uncovered. Elytra darker toward the sides. Abdomen: 9-segmented, with five ventrites (segments III-VII), segments VIII and IX internal. Segment IX with appendiculate, slender, paratergites, with minute spines on inner margin and setose apically (Figures 2A-B). Genitalia: Aedeagus with transverse tegminal plate, tegminal struts abruptly bent at base; lateral lobes setose, fused to tegminal plate; median lobe narrow at apex, wide at base, curving forward at base (Figures $2 \mathrm{C}-\mathrm{E})$.
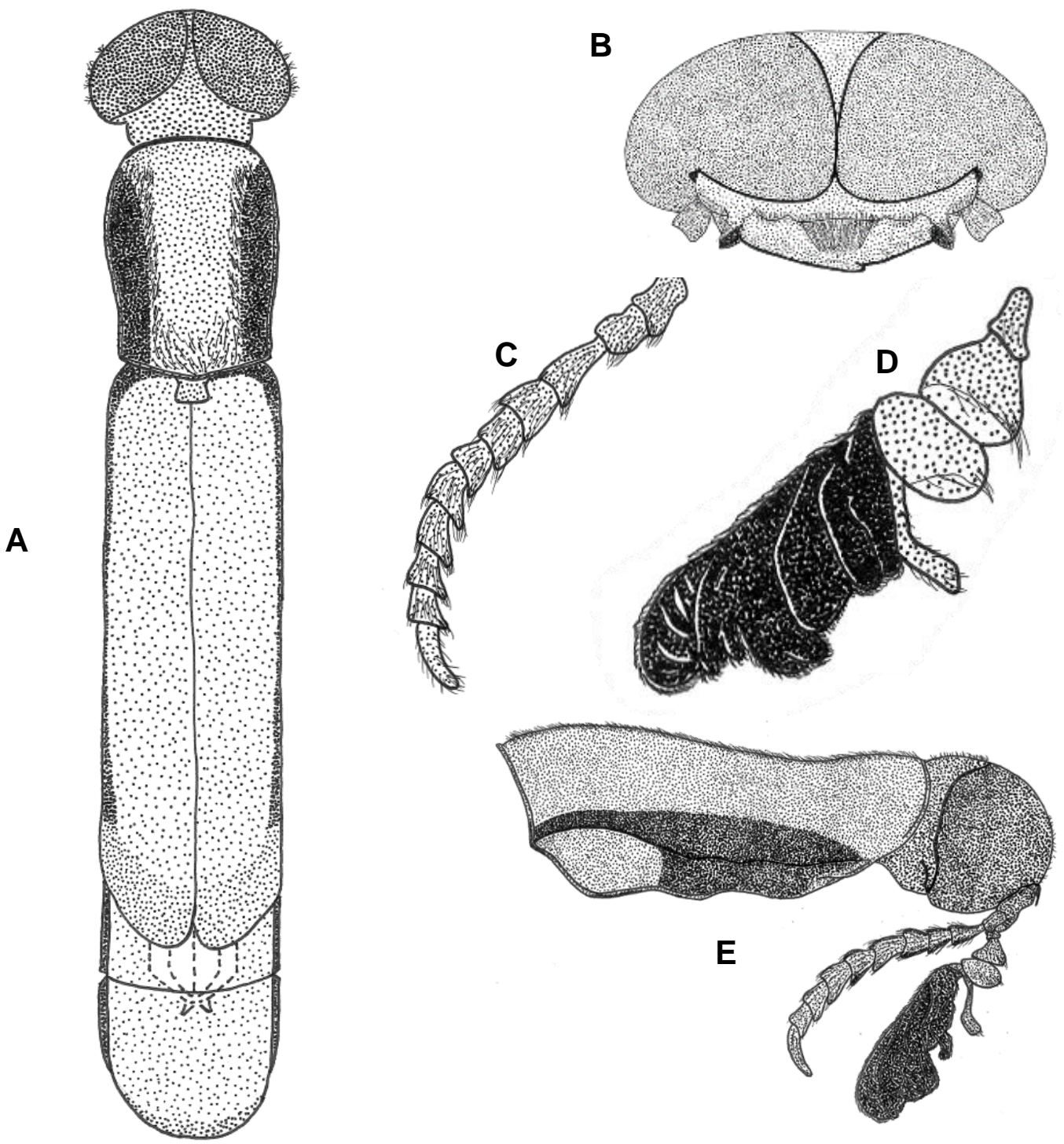

Figure 1. Melittomma pilzi n. sp. Holotype. A) Body. B) Head. C) Antenna. D) Maxillary palp. E) Lateral view of 
pronotum.
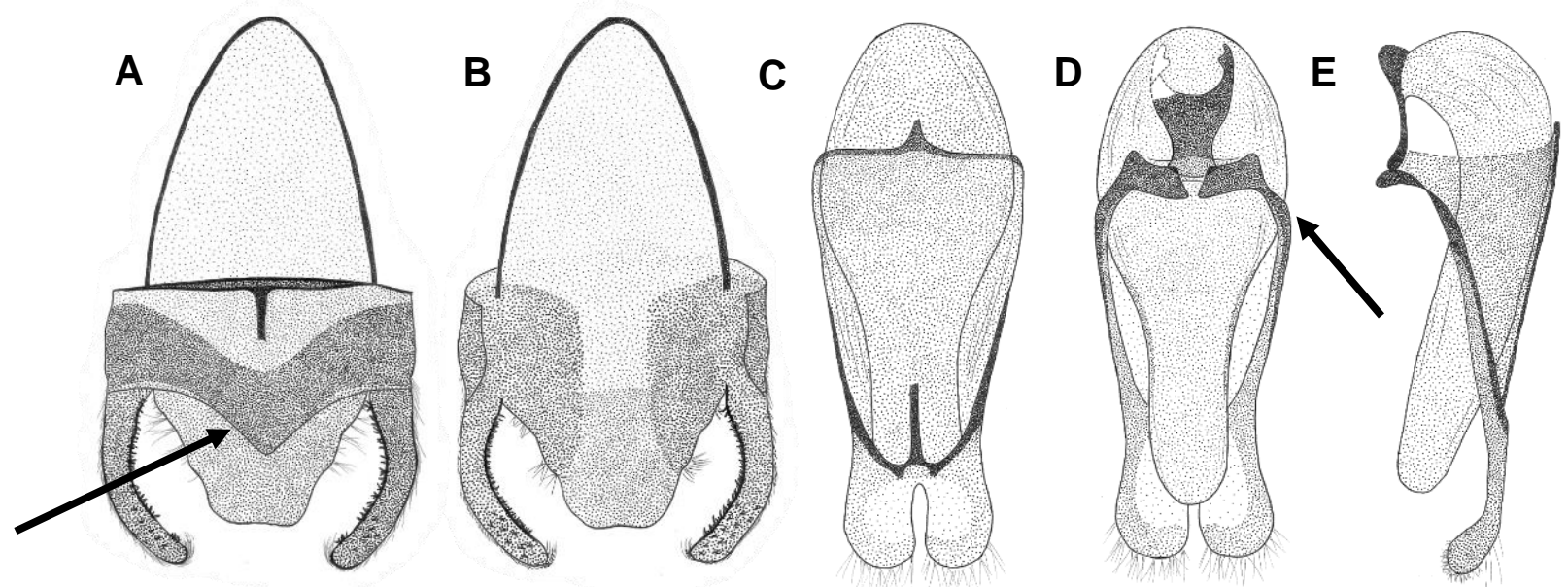

Figure 2. Melittomma pilzi n. sp. Male genitalia. A) Abdominal sternites VIII and IX (Arrow indicates basomedian projection on distal margin of sternite IX). B) Abdominal tergites VIII and IX. C) Aedeagus, dorsal. D) Aedeagus, ventral (arrow indicates abrupt bent at base of tegminal strut). E) Aedeagus, lateral.

A

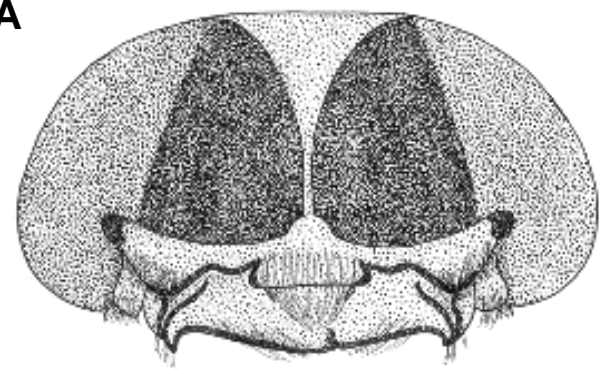

B

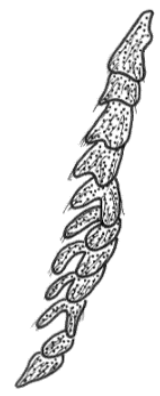

C

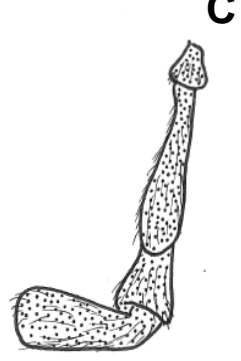

Figure 3. Melittomma pilzi n. sp. Female allotype. A) Head. B) Antenna. C) Maxillary palp.

Allotype. Female (Figure 3). Similar to holotype except for the following. Head: Eyes frontally separated in front by a small space (Figure 3A). Antennomeres 3-10 biramous (Figure 3B). Maxillary palps without a palporgan (Figure 3C). Thorax: Tibial spur formula 1-22. Abdomen: 6 ventrites present. Segments VII to IX less than half as wide as sternite VI. Genitalia: Coxites short, styli setose, longer than coxites.

Etymology. We name this species in honor of George E. Pilz, botanist who dedicated his life to exploring
Honduran biodiversity and who spent his last 34 years at Zamorano University, Honduras.

Diagnosis: Melittomma pilzi can be easily separated from other Honduran lymexylids (see key) based on body size, coloration, length of elytra, and male genitalia. The other species from Honduras in the genus, Melittomma brasiliense, is a larger and more robust beetle (up to $27 \mathrm{~mm}$ ) with a markedly different male genitalia (Figure 4) and with five abdominal ventrites in both sexes. 

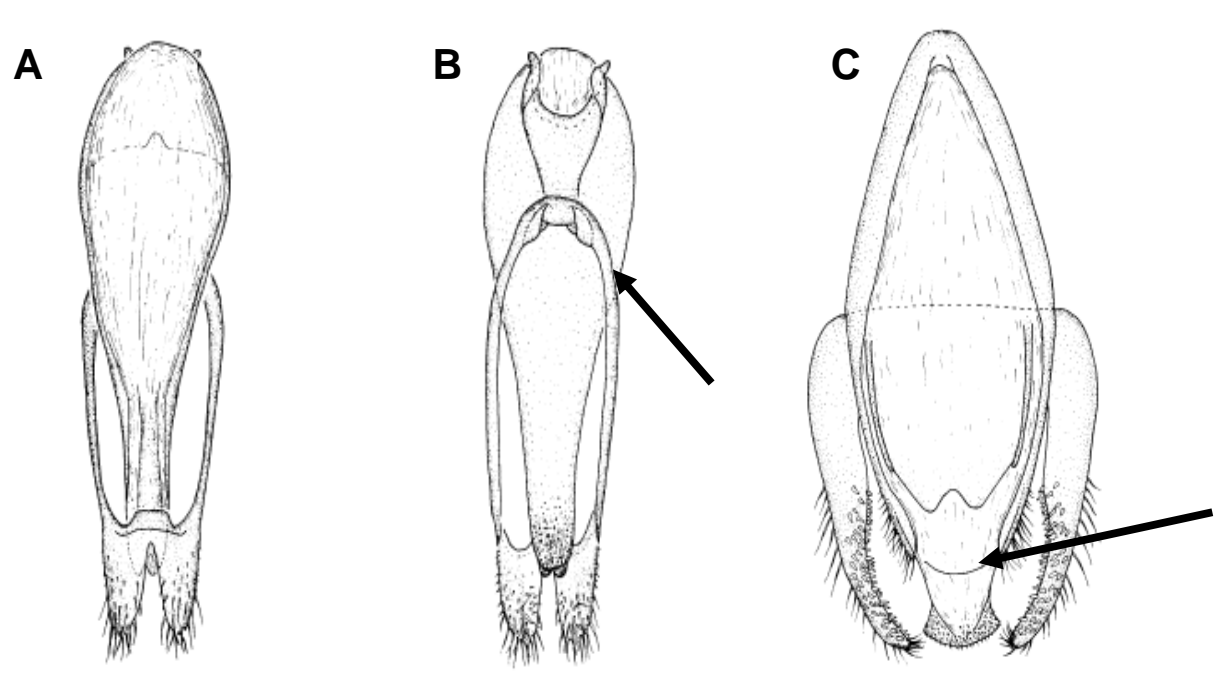

Figure 4. Melittomma brasiliense male genitalia (From Wheeler 1986) A) Aedeagus, dorsal. B) Aedeagus, ventral (arrow indicates gradually curved base of tegminal strut). C) Sternites VIII and IX (arrow indicates distal margin of sternite IX evenly rounded).

\section{Key to the Species of Honduran Lymexylidae}

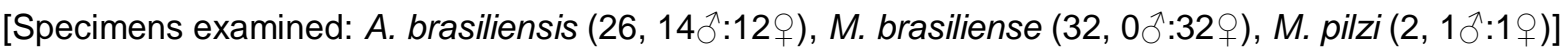

1 Elytra short, not covering hind wings. Color dark brown

Atractocerus brasiliensis (Lepeletier and Audinet-Serville)

1' Elytra long, covering hind wings. Color light brown.

2 Body length $\sim 10 \mathrm{~mm}$. Distal margin of abdominal sternite IX of male with basomedian projection (Figure 2A). Tegminal struts of male genitalia abruptly bent at base (Figure 2D). Female with six abdominal ventrites Melittomma pilzi Orozco and Díaz

$2^{\prime} \quad$ Body length $>13 \mathrm{~mm}$. Distal margin of abdominal sternite IX of male evenly rounded (Figure 4C). Tegminal struts of male genitalia gradually curved at base (Figure 4B). Female with five abdominal ventrites

Melittomma brasiliense (Laporte)

Acknowledgments. We thank Ron Cave and Abelino Pitty for their helpful comments to the manuscript.

\section{References}

Casari, S.A. and E.P Teixeira. 2011. Larva of Atractocerus brasiliensis (Lepeletier \& Audinet-Serville, 1825) (Lymexylidae, Atractocerinae). Papéis Avulsos de Zoologia 51(12):197-205.
Wheeler, Q. 1986. Revision of the genera of Lymexylidae (Coleoptera: Cucujiformia). Bulletin of the American Museum of Natural History 183:117-209.

Received for publication 14 November 2017.

Accepted 29 November 2017.

Published 12 February 2018. 